\title{
Optical Sensing Material for Dissolved Oxygen: Covalent Immobilization of Tris(4,7-diphenyl-1,10-phenanthroline)ruthenium(II) Complex in Sol-Gels
}

\author{
Yong Chae Jeong, Ok-Jae Sohn, Jong II Rhee, Sunwoo Lee, and Hyung Jin Kim* \\ Center for Functional Nano Fine Chemicals, School of Applied Chemical Engineering, Chonnam National Lniversity, \\ Guangit 500-757, Korea. E-mail: hungkimachomam ackr \\ ${ }^{\dagger}$ Department of Chemistrv, Chonnam National Lnwersity, Gwangiu 500-757, Korea \\ Received February 9, 2007
}

Key Words : Covalent immobilization. Sol-gel. Optical sensor. Ru(II) complex. Dissolved oxygen sensor

In recent years. much effort has been devoted to the development of optical sensors for dissolved oxygen (DO). because dissolved oxygen measurements in an aqueous environment are widely used in the biological. ${ }^{1}$ environmental, ${ }^{\hat{}}$ and industrial ${ }^{\hat{3}}$ areas.

The most common types of optical oxygen sensing materials are based on the dynamic quenching of the luminescence of dye molecules inmobilized within a solid substrate. Therefore, the performance of the optical sensors strongly relies on the ability of the solid substrate to immobilize the oxygen-sensitive luminophore. To date. various solid substrates have been explored. including cellulose acetate. ${ }^{+}$ fluoropolymers. ${ }^{5}$ ion-exchange polymers, ${ }^{6}$ poly(methyl methacrylate) ${ }^{7}$ poly(styrene), ${ }^{8}$ poly(vinyl chloride), ${ }^{9}$ silicone rubber, ${ }^{j(1,13}$ and sol-gel matrices. ${ }^{11}$ Aniong these materials. sol-gel matrices are increasingly utilized to develop sensing materials. due to their superior chemical stability. optical transparency and porosity. ${ }^{12}$

Ruthenium(II) polypyridyl complexes are attractive fluorophores for use in fluorescence-based oxygen sensors owing to their high photochemical stability, high molar absorptivity. long lifetime derived from the metal to ligand charge transfer (MLCT) excited states. and large Stokes shift. ${ }^{13.16}$ The inmobilization of such Ru(II) complexes on sol-gel matrices has been recently investigated for the development of optical sensors. ${ }^{17.21}$ Although most of these investigations involved the encapsulation (including impregnation and doping) of dye molecules into sol-gels. these methods could cause leaching of small dye molecules from the host sol-gels into the analy te solution during liquid-phase sensing. thereby reducing the sensor lifetime. To circumvent this leaching problem, an alternative method can be used involving the covalent binding of the dye molecules on the sol-gels. Therefore. in order to develop oxygen-sensing materials having long-term stability without any leaching problems. we explored the covalent immobilization of fluorophores in sol-gels. Herein, we report the preparation of an optical sensing material based on the covalent immobilization of a $\mathrm{Ru}(\mathrm{II})$ comiplex on a porous sol-gel matrix.

The tris(4.7-diphenyl-1,10-phenanthroline)ruthenium(II) coniplex $\left[\mathrm{Ru}(\mathrm{dpp})_{3}\right]$ (1. Fig. 1) is the fluorophore of choice in this work, since it is a well-known fluorescent dye which is quenched dynamically by molecular oxygen. ${ }^{15}$ To our

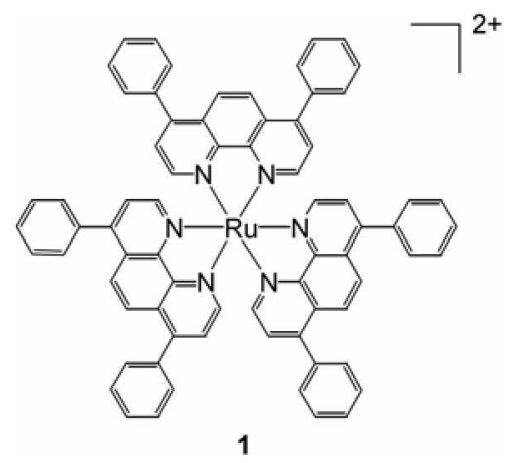

Figure 1. Tris(4,7-dipheny 1)-1,10-phenanthroline)rnthenium(II) complex $\left[\mathrm{Ru}\left(\mathrm{dpp} \mathrm{j}_{3}\right]\right.$.

knowledge. the covalent immobilization of Ru(II) complex 1 in sol-gels has not previously been reported.

In our previous work."- we described the synthesis of the mis(4,7-diphenyl-1, 10-phenanthroline)ruthenium(II) complex (2) possessing a hydroxypropyl group. which is able to react with reactive silicate precursors such as 3-(triethoxysilyl)propyl isocyanate, 3-(glycidoxy)triethoxysilane, or 3chloropropyltriethoxysilane. With this complex 2 in hand, we initially attempted to prepare a sol-gel precursor, 4 . linked with $\mathrm{Ru}(\mathrm{dpp})_{3}$. Which can be readily bound to solgels. Thus. the chemical bonding of complex 1 to a silicate precursor was achieved by the reaction of complex 2 with a slight excess (1.2 eq.) of 3-(triethoxysilyl)propyl isocyanate (3) in boiling tetrahydrofuran in the presence of trietlyyamine as a catalyst under a nitrogen atmosphere to afford the precursor + in good yield (Scheme 1). A small amount of unreacted complex 2 was observed in thin layer chromatography on silica gel eluting with a 20:1:1 mixture of $\mathrm{CHCN} /$ saturated aqueous $\mathrm{KNO}_{3} / \mathrm{H}_{2} \mathrm{O}$. The $\mathrm{R}_{f}$ values are 0.60 for the complex 2 and 0.55 for the silicate derivative 4 , respectively. The coupling between the two components was confirmed by the formation of a carbamate moiety $\left(-\mathrm{NHCO}_{2}-\right)$. which was characterized by the corresponding stretching vibrations (FT-IR) both at $3300 \mathrm{~cm}^{-1}(\mathrm{~N}-\mathrm{H})$ and $1700 \mathrm{~cm}^{-1}(\mathrm{C}=\mathrm{O})$. Further structural confinmation of $\mathcal{A}$ was supported by the molecular peak (MALDI-TOF MS) at 1403.49 for $\left[\mathrm{M}-2 \mathrm{PF}_{6}\right]^{2}$.

The covalent immobilization of $\mathrm{Ru}(\mathrm{dpp})_{3}$ in the sol-gel matrix (Ml) was accomplished by the reaction of the silicate derivative 4 with a sol-gel solution containing tetraethyl- 


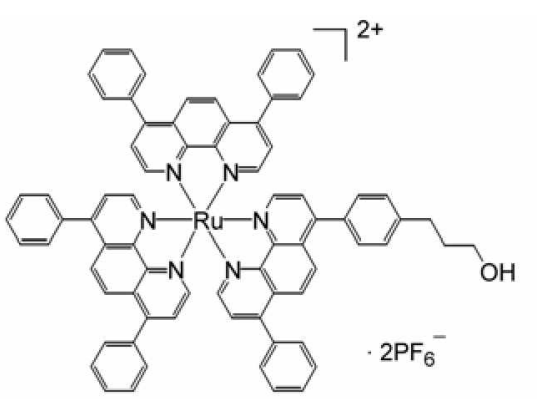

2

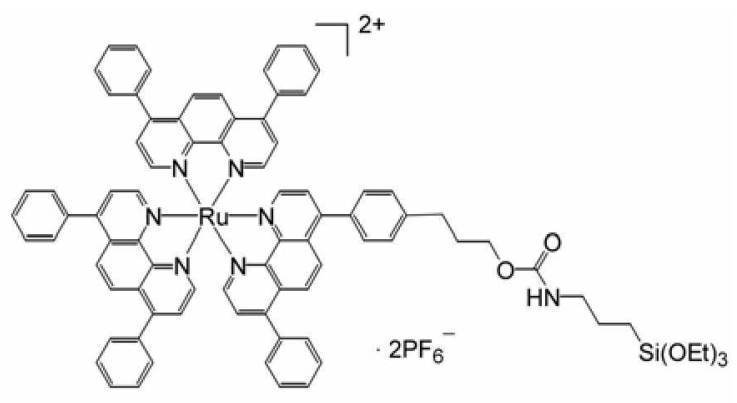

4

Scheme 1

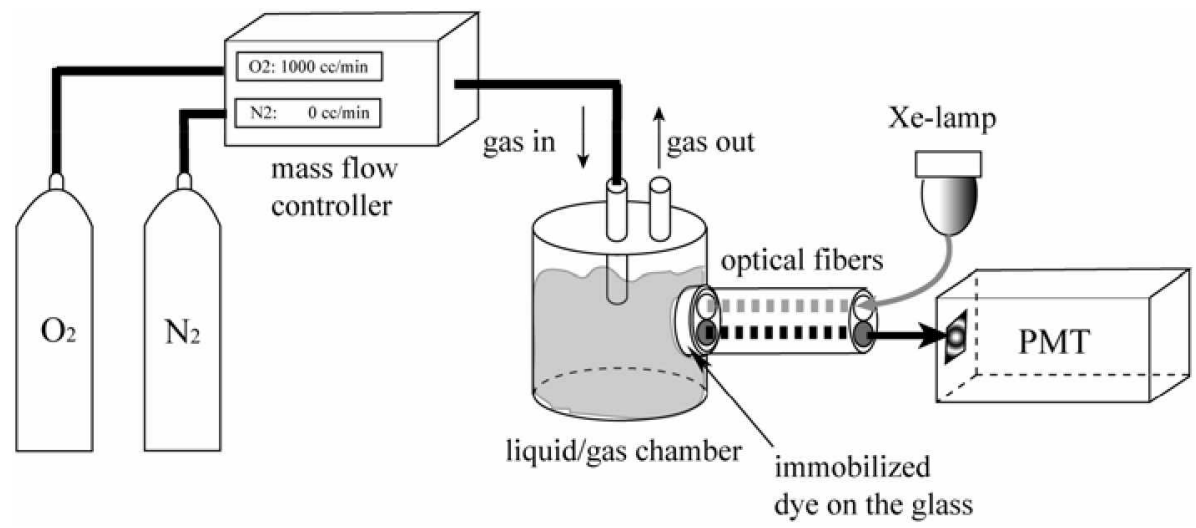

Figure 2. Schematic of experimental system used to measure the fluorescence intensity of the sensing membranes.
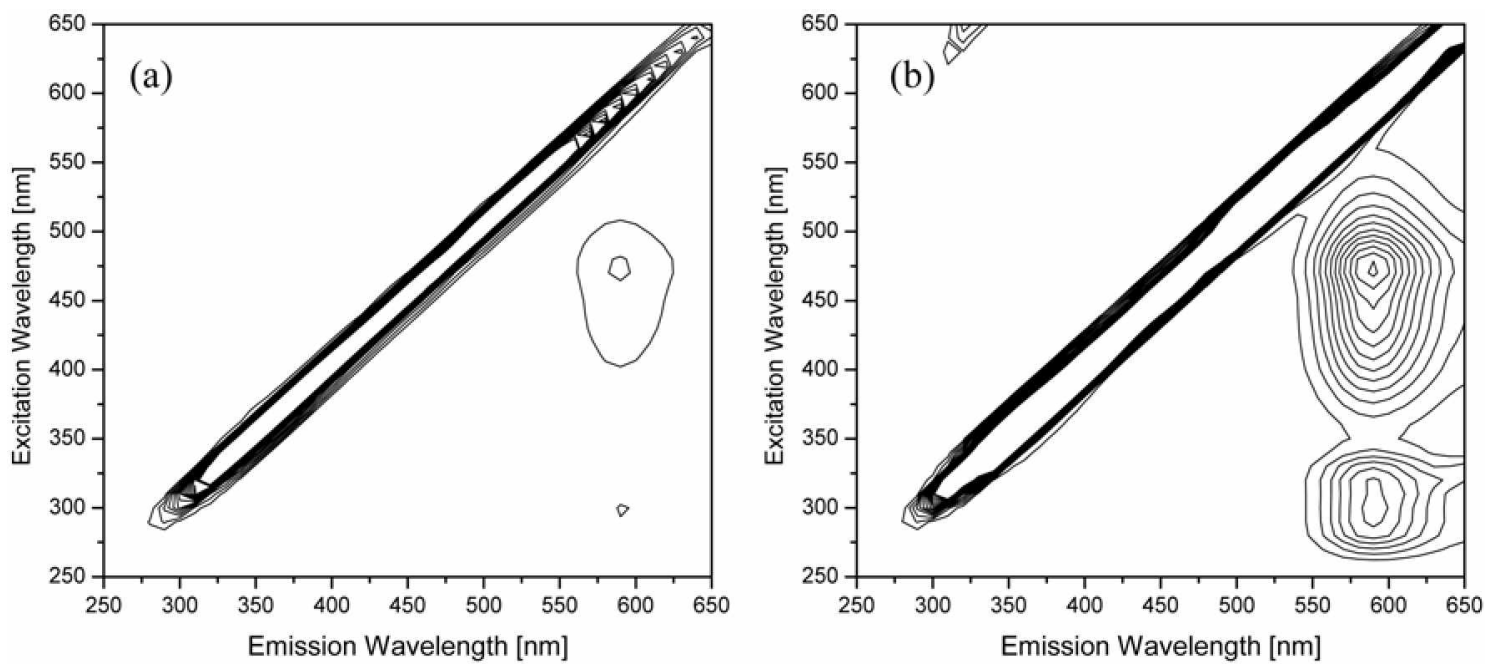

Figure 3. 2D fluorescence spectra of the sensing membrane $\mathrm{Ml}$ in aqueous solution saturated with $\mathrm{O}_{2}$ (a) and $\mathrm{N}_{2}$ (b).

orthosilicate (TEOS) under acidic conditions. TEOS is one of the most widely used sol-gel precursors for immobilizing optical sensors in sol-gels. ${ }^{12}$ The sensing membrane was obtained by casting a fixed volume of the sol-gels onto a microscopic slide with a manual pipetting teclunique. For comparison purposes, the doped sol-gel membrane (M2) was also prepared from the mixture of $\operatorname{Ru}(\mathrm{dpp})_{3}$ (1) and the same sol-gel solution.

The 2D fluorescence spectra of the covalently immobilized sensing membrane (Ml) are shown in Figure 3. Like $\mathrm{Ru}(\mathrm{dpp})_{3}, 2$ this mentbrane exhibits a strong fluorescence enission at $590 \mathrm{~mm}$ when excited by radiation of $470 \mathrm{~nm}$ in aqueous media de-aerated by bubbling $\mathrm{N}_{2}$ gas. As expected, the fluorescence emission intensity was reduced by the quenching process when the membrane was exposed to an aqueous solution saturated with $\mathrm{O}_{2}$ gas. Figure 4 shows the typical quenching response of the sensing membrane, Ml, towards the same concentration of dissolved $\mathrm{O}_{3}$. This test was perfomed by continuously exposing the sensing membrane to a mixture of dissolved $\mathrm{O}_{2}$ and $\mathrm{N}_{2}$ obtained by bubbling the two gases. The membrane, $\mathrm{Ml}$. is regenerated by flushing with $\mathrm{N}_{2}$ gas. and there was no drift in any of the 


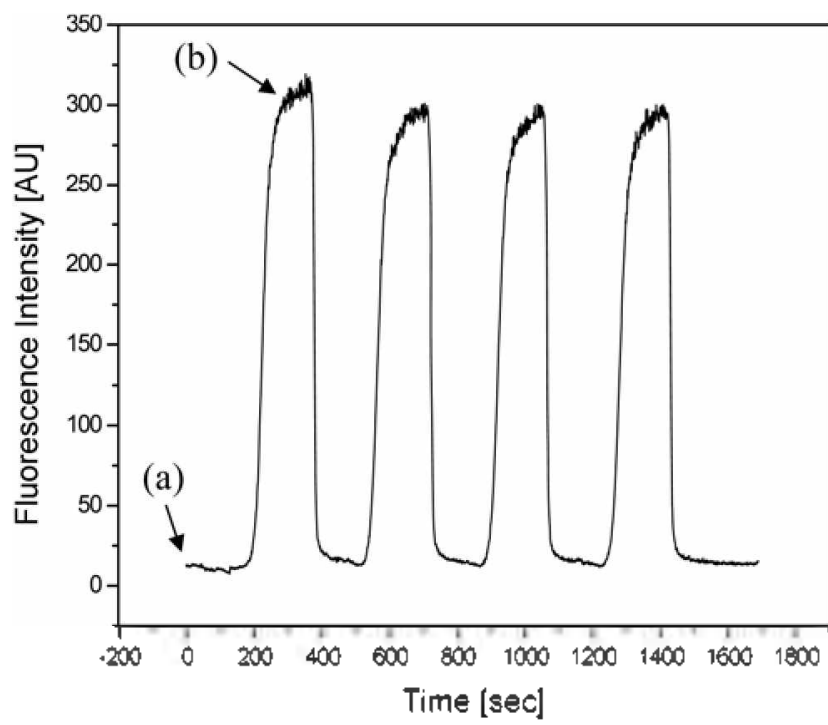

Figure 4. Quenching response of the sensing membrane $\mathrm{Ml}$ to dissolved oxygen when the solution is saturated with $\mathrm{O}_{2}$ (a) and $\mathrm{N}_{2}$ (b). Excitation at $470 \mathrm{~cm}$, fluorescence observed at $590 \mathrm{~cm}$.

signal changes. indicating that membrane $\mathrm{Ml}$ can therefore be used for repeated measurements.

To compare the extent of dye leaching in order to evaluate their long-term operation, the sensing membranes, MI and M2, were soaked in distilled water separately. Periodically. the nembranes were removed from the water and their fluorescence intensities were measured at $590 \mathrm{~lm}$ with an excitation wavelength of $470 \mathrm{~nm}$. As depicted in Figure 5 . in the case of membrane $\mathrm{M} 2$. Ru(dpp) 3 leached out of the membrane and only about $40 \%$ of the Ru(dpp) $)_{3}$ originally present in the gels was retained after 40 days. In contrast. the Ru(dpp $)_{3}$ in membrane $\mathrm{Ml}$ did not leach during the same time period. These results demonstrate that their covalent immobilization in gels prevents the dye molecules from leaching out of the matrix. although a slight decrease of the emission intensity for membrane Ml was observed during

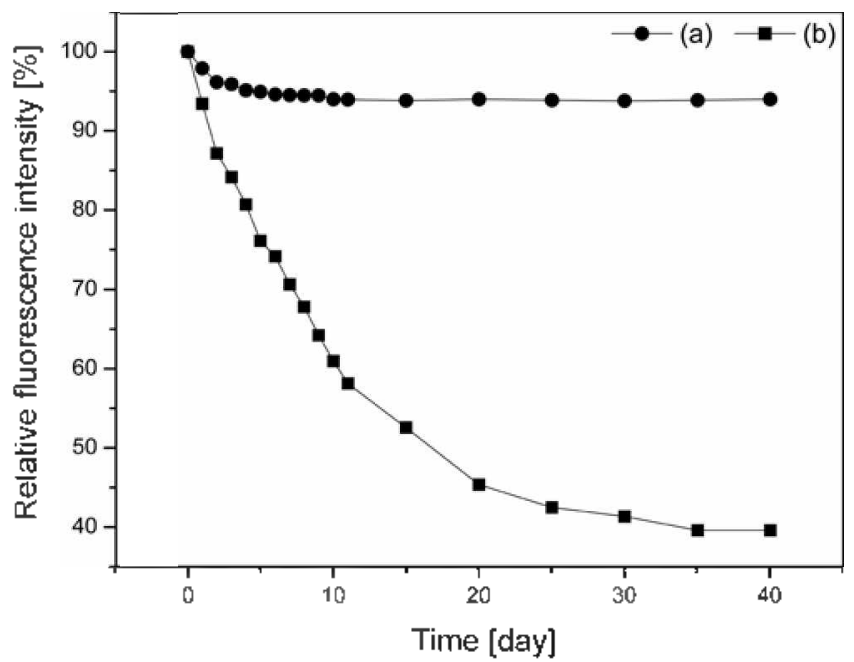

Figure 5. Leaching of the dye molecules from the membranes $\mathrm{Ml}$ (a) and $\mathrm{M} 2$ (b) in water. the initial stage of the experiment. This decrease in intensity is probably due to the leaching of the unreacted complex 2 within the gels. In addition, we found no changes in the fluorescence intensity when membrane Ml was kept in air for three months.

In conclusion. the silicate derivative of the fluorophore. Ru(dpp), was synthesized and firmly bound to a TEOSbased sol-gel matrix through covalent bonding to provide a suitable optical sensing membrane for dissolved oxygen measurements. This membrane showed long-term stability and repeatability. The leaching of the dye was prevented by its covalent immobilization in a sol-gel matrix

\section{Experimental Section}

IR spectra were recorded on a Shimadzu FTIR- 8300 spectrophotometer. MALDI-TOF mass spectral data were obtained on a Voyager DE-STR proteomics analyzer. The optical properties were measured with a Hitachi F-4500 fluorescence spectrophotometer. All reagents were obtained from Aldrich Chemical $\mathrm{Co}$. and used without further purification. THF was dried by refluxing with benzophenone/ $\mathrm{Na}$ under an $\mathrm{N}_{2}$ atmosphere. Complex 2 was prepared according to the reported procedure.?

Preparation of sol-gel precursor linked with tris $(4,7$ diphenyl-1,10-phenanthroline)ruthenium(II) complex (4). A mixture of complex 2 (33 $\mathrm{mg}$. $0.026 \mathrm{mmol}$ ). 3 (triethoxysilyl)propyl isocyanate $(3.7 .65 \mathrm{mg} .0 .031 \mathrm{mmol}$ ), and $\mathrm{Et}_{3} \mathrm{~N}$ ( 3 drops) was refluxed in dry THF for $6 \mathrm{~h}$ under an $\mathrm{N}_{2}$ atmosphere. After cooling to $25^{\circ} \mathrm{C}$, the reaction mixture was filtered and the filtrate was concentrated in vacho to afford the silicate precursor $+(23 \mathrm{mg}, 63 \%)$ as a brown liquid. which was used for the preparation of the sensing membrane without further purification. FT-IR (KBr) 3300 $(\mathrm{N}-\mathrm{H}) .3000(\mathrm{C}-\mathrm{H}) .2220$ (NCO). $1700\left(\mathrm{NHCO}_{2}\right) .1070 \mathrm{~cm}^{-1}$ (C-O). MALDI-TOF MS for $\mathrm{C}_{85} \mathrm{H}_{75} \mathrm{~F}_{12} \mathrm{~N}_{7} \mathrm{O}_{5} \mathrm{P}_{2} \mathrm{RuSi}$ : calcd 1693.39. found $1403.49\left[\mathrm{M}-2 \mathrm{PF}_{\mathrm{i}}\right]^{2+}$.

Preparation of sensing membranes (M1 and M2). Microscopic slides were used as solid supports onto which the sol-gel was cast. Prior to their use. the surface of the microscope slides was activated by treating it with $1 \mathrm{~N} \mathrm{HF}$ solution for ca. $2 \mathrm{~min}$, followed by washing with distilled water and $\mathrm{MeOH}$, and then dried at $25^{\circ} \mathrm{C}$. A sol-gel solution was prepared by mixing tetraethyl orthosilicate $(0.67 \mathrm{~mL}, 3$ mumol). ethanol ( $340 \mu \mathrm{L}, 6 \mathrm{mmol})$, water $(108 \mu \mathrm{L} .6 \mathrm{mmol})$ and $0.1 M \mathrm{HCl}$ solution ( $3 \mu \mathrm{L}, 0.3 \mu \mathrm{mol}$ ). For the preparation of the covalent immobilized sol-gel membrane (Ml). the silicate derivative $4(120 \mu \mathrm{g} .137 \mu \mathrm{mol})$ was added to the above sol-gel solution and the mixture was stirred for $4 \mathrm{~h}$ at $25^{\circ} \mathrm{C}$. The resulting mixture was spread on the microscope slide and dried at $25^{\circ} \mathrm{C}$ for $24 \mathrm{~h}$. after which a glassy membrane was formed and it was finally dried at 80 ${ }^{\circ} \mathrm{C}$ for $12 \mathrm{~h}$.

For the preparation of the doped sol-gel membrane (M2). $\mathrm{Ru}(\mathrm{dpp})_{2} 2 \mathrm{PF}_{6}{ }^{-}(1.9 \mathrm{mg} .137 \mu \mathrm{mol})$ was added to the above sol-gel solution and the mixture was stirred for $4 \mathrm{~h}$ at $25^{\circ} \mathrm{C}$. The resulting mixture was spread on the microscope slide 
and dried at $25^{\circ} \mathrm{C}$ for $24 \mathrm{~h}$, and funally dried at $80^{\circ} \mathrm{C}$ for $12 \mathrm{~h}$.

Measurement of fluorescence intensity. The fluorescence spectra and response data of the sensing membranes were obtained with a $2 \mathrm{D}$ fluorescence spectrophotometer (Model F-4500. Hitachi. Japan). The 2D fluorescence spectrophotometer was connected by a $2 \mathrm{~m}$ bifurcated liquid light conductor (Lumatec $\mathrm{GmbH}$, Germany) to a dyeimmobilized sensor membrane on a glass slide in the port of a $10 \mathrm{~mL}$ stainless steel gas flow chamber (Fig. 2). Thus. there was no interference from light outside the chamber. The measurement conditions of the spectrophotometer were as follows: scanning speed, $30,000 \mathrm{~nm} \mathrm{~min}^{-1}$. PMT voltage. $950 \mathrm{~V}$; excitation wavelength range. 250-650 $\mathrm{nm}$; entission wavelength range $250-650 \mathrm{~lm}$; excitation and emission slits. $10 \mathrm{~km}$. The desired concentrations of oxygen in water were obtained by passing pure $\mathrm{N}_{2}$ and $\mathrm{O}_{2}$ gas through the chanber using coniputer-controlled mass flow controllers (Model GFC 171. Aalborg. USA) with a constant flow rate of 1 $\mathrm{L} \cdot \mathrm{minh}^{-1}$.

Leaching experiment. After aging, each sensing membrane on the glass slide was washed several times with $\mathrm{CHCl}_{3}$, and immersed in $100 \mathrm{~mL}$ of distilled water in a leaching vessel continuously shaken at roon temperature. The membranes were periodically withdrawn, placed into the flow chanber. and their fluorescence intensities were measured. The membranes were then returned to the leaching vessel containing fresh distilled water. The extent of dye leaching was deternined by calculating the relative decrease in the fluorescence intensity of each sensing mentbrane compared with the initial value.

Acknowledgement. This work was supported by grant no. RTI04-03-03 from the Regional Technology Lnovation Program of the Ministry of Commerce. Industry and Energy (MOCIE).

\section{References}

1. Ongen Sensing. Methods in Etrzymology 381: Sen. C. K.: Semenza. G. L., Eds.: Academic Press: San Diego, 2004.

2. (a) Sojka. R. E.; Oosterhuis, D. M.: Scott. H. D. In Handbook of Photosymthesis, $2^{\text {nd }}$ ed.: Pessarakli, M. Taylor \&Francis: Boca Raton. FL. 2005: p 299. (b) Taylor. L. A.: Cooper. B.: McKay. D. S.: Colson. R. O. Miner. Hetal. Proc. 1993. 10.43.

3. (a) Whiftin. V. S.: Cooney. M. I.: Cord-Ruwisch. R. Biotechnol. Bioeng. 2004. $85,422-433$. (b) Kebabian, P. L.: Romano. R. R: Freedman, A Meas. Sci. Techol. 2003. 14. 983. (c) Fitzgerald. M: Papkovsky. D. B.: Smiddy, M.; Kerry, J. P.: O Sullivan. C. K: Buckley. D. T.: Guilbault. G. G. J. Food Sci. 2001. 66. 105.

4. Douglas. P. Eatont. K. Sens. Actuators, B: Chent 2002. 82.200.

5. Anlao. Y.: Ishikawa. Y.: Okura. I. Anat Chin Acta 2001. 45. 177.

6. Vasilev, V. V.: Borisov, S. M. Sens. Actuators, B: Chem. 2002.82. 272.

7. Mills. A.: Thomas. M. Analyst 1997. 122,63.

8. Hartmant1. P.: Leiner. M. T. P.: Lippitsch. M. E. Anal. Chem. 1995. 67.88

9. Hartmatun. P.: Trettnak. W. Anal. Chem 1996. 68.2615.

10. Li. X. M.: Ruan. F. C.: Wong, K. Y. Analyst 1993, 118. 289.

11. MeDonagh. C.: MacCraith. B. D.: MeEvov, A. K. Anal Chem. 1998. 70,45 .

12. Mac Craith. B. D.: McDonagh. C.: McEvoy. A. K.: Butler. T.: O'Keeffè. G.: Murphy. V. T. Sol-Gel Sci. Tech. 1997.8. 1053.

13. Bacont. T. R.: Demas. J. N. Anal Chent 1987. 59. 2780

14. Carraway, E. R.: Demas, J. N.: DeGraff. B. A.; Bacon. J. R. Anal. Chem $1991,63,337$.

15. Li. X.-M : Ruan, F.-C: Ng, W.-Y.: Wong, K.-Y. Sensors Actuators 1994. B21, 143

16. Demas. T. N.: DeGrafť. B. A. Anal. Chem. 1991. 63. 829A.

17. MacCraith. B. D.: McDonagh. C. M.: O'Keeffè. G. E.: Keyes. T.: Vos. I. G: O'Kelly. B.: McGilp. .' F. Anahst 1993. 118. 385.

18. Hartmann. P. Leiner, M. J. P. Anal. Chem 1995, 67, 88.

19. Giordano, P. J.: Bock. C. R.; Wrighton. M. S. J. Am. Chem. Soc. 1978. 100,6960 .

20. Case. F. H.: Strohm. P. F. J. Org. Chent 1962. 27. 1641

21. Watts. R. J: Crosby. G. A. J.An. Chen. Soc. 1971.93. 3184.

22. Kim. H. T.: Teong. Y. C.: Rhee. J. I.: Kim. T. H. Bull. Korean Chem. Soc. 2006, 27. 2084. 